\title{
The use of isiXhosa children's poetry as a tool to integrate literacy, mathematics and life skills in Foundation Phase: Grade R-3
}

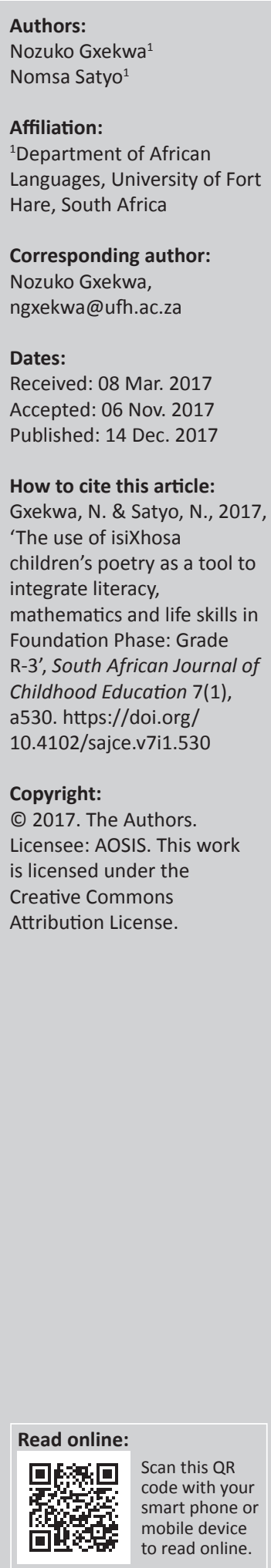

Literature helps us understand and make sense of the world around us. It is a part of education, which broadens one's mind about how to understand, transfer knowledge and provide meaningful and authentic learning. Thus, this article aims to highlight how some elements of isiXhosa children's poetry can be used to help pre-service teachers to teach and integrate mathematics and life skills with literacy in Foundation Phase (FP). This approach of using poems for integration strengthens concepts and skills in more than one subject area. The theoretical framework that informed the article is integrative learning. The data in this article were generated through non-participant classroom observations and non-structured interviews with the participants of the study and the researchers adopted the interpretative phenomenological analysis method for data analysis. This article was prompted by findings of lack of understanding of integrative teaching and learning and lack of teaching resources in isiXhosa to enhance integrative teaching and learning in FP intervention undertaken with 25 first year isiXhosa-speaking FP students.

\section{Introduction and background}

Education that helps students to connect ideas across and within subject domains encourages creativity and innovation (Harlen 2010:5). In this study, the inquiry was the pre-service teachers' knowledge of integrative learning and how they implement it in their Foundation Phase (FP) classrooms using isiXhosa as Language of Learning and Teaching (LOLT). Language Policy of Foundation Phase requires that educators use the first language of the learners and the participants in the study are isiXhosa speakers; thus, isiXhosa is the LOLT in the study. The integration that is the main focus of the study is between language and two scientific subjects, namely mathematics and life skills in FP. Kok and Van Schoor (2014:96) state that by implication, science teacher educators of FP student teachers are required to prepare their students with the pedagogical content knowledge to teach science in an integrated manner. Such an approach strengthens concepts and skills in more than one subject area. Children learn language and mathematics best as they engage in meaningful and connected experiences. They express their mathematics knowledge by identifying attributes of a geometric shape, citing examples of geometric shapes found in the real world, and writing and illustrating poems about geometric concepts and numbers. Harlen (2010:4) have this to say about integration of subjects, especially science: it is situations where science is used in daily life, and which are likely to capture the interest of many students that often involves combining science with other subjects, particularly technology and mathematics.

South African FP teachers have to teach a life skills curriculum, which integrates many traditional subjects and includes science and the technological process. The Curriculum and Assessment Policy Statement for this subject area in FP aims to strengthen learner awareness of social relationships, technological processes and elementary science (DBE 2011). It further stipulates that education policy for life skills does not overtly advocate an integrated approach; it implies an integration of language, science, technology and social issues in stating, as a specific aim (DBE 2011). This kind of integrated curriculum is essential for long-lasting understanding and teacher education should supply this experience if teachers are to be equipped to help students progress towards the goal of understanding these ideas.

The purpose of the article is to highlight the use of isiXhosa children's poems as a tool to integrate language, mathematics and life skills in FP: Grade R-3. The article addresses the following questions: (1) what is integrative teaching and learning? (2) What role can isiXhosa children's poetry play in integrative teaching and learning? 


\section{Theoretical and conceptual framework of the research}

This article examines and highlights the advantages of using isiXhosa children's poetry as a tool to enhance teaching and learning by integrating language, mathematics and life skills in FP, and the theory that informs this article is integrative learning theory. Integrative learning theory is a theory that describes a movement towards integrated lessons, thus helping learners to make connections within subjects. Elliot (2010:23) stipulates that integrated learning units provide students with opportunities to work towards meeting expectations from two or more subject matters. Teachers using an integrated approach ensure that specific knowledge and skills for various subjects are incorporated into plans that link expectations from different subject areas. Integrated learning combines what one learns in the classroom, whether it is theory or technique, with the solution of real-world problems.

These integrated learning experiences provide students with multiple opportunities to reinforce and demonstrate their knowledge and skills in a range of contexts.

\section{Literature review}

Kok and Van Schoor (2015:96) looked at how science concepts can be learnt by way of integrated science-technology-society (STS) approach. They used children's literature and technology to teach science concepts in a life skills programme in FP. The authors of the study used short stories and technology to teach a life skills lesson in an FP class. The short story used in this study was role-played and videos were produced. The theme of the story highlighted the outcomes of the lesson. This activity is evidence of three integrated learnings: language, life skills and technology.

Langhorst, Ehlert and Fritz (2013:9) investigated a development-oriented mathematics programme with special consideration of phonological processing aspects. They used activities integrated in their daily routines and developed mathematics through stories with demonstration between mathematics and language focusing on phonological awareness and phonological memory.

Schafer and Wilmot (2015:63) focused on integration of visual arts and mathematics by examining visual arts and the teaching of mathematical concepts of shapes and space in Grade R classrooms. They further said, as teacher educators, they observed that creative art activities are not being used cross-curricularly in many Grade R classrooms and classroom displays show little evidence of children's expressions of the understandings and meanings, specifically as these pertain to children's concepts of shape and space.

Nompula (2012) investigated strategies for integrated learning experiences and instruction in the teaching of creative art subjects. She highlighted that ideally an integrated approach enables a pupil to learn concepts from several cognitive and experiential points of view.
The purpose of this article is to add to knowledge regarding integration of learning areas by demonstrating how isiXhosa children's poetry can be used as a tool to integrate language, life skills and mathematics.

\section{Research method}

This study was a case study focusing on the practice of preservice teachers participating in the FP programme at a particular university of technology. Zainal (2007:1) explains that a case study is a method that enables a researcher to closely examine data within a specific context. In most cases, a case study method selects a small geographical area or a very limited number of individuals as the subjects of the study. This study uses an interpretive case study as the researchers interpreted the data by developing conceptual categories, supporting or challenging ideas connected to them.

\section{Data collection}

Data generated in this study were collected using nonparticipant classroom observations and one-on-one nonstructured interviews with the participants of the study.

\section{Non-participant classroom observations}

One of the researchers accompanied one of the evaluators for FP during practice teaching and the focus was on subject matter and integrative teaching and learning. The researcher played the role of a non-participant observer while gathering data.

In non-participant observation, objectivity or neutrality can be maintained. The observer in this type of observation gives a detached and unbiased view about the group (Choudhury, 2016). The researcher was a non-participant observer focusing on the teaching and learning strategy and teaching materials that the participants used to integrate learning areas.

\section{One-on-one non-structured interviews}

The one-on-one interview in this study played the role of a reflection tool for the lessons observed. Most interpretative phenomenological analysis (IPA) studies have been conducted through the use of a semi-structured interview. This form of interview allows the researcher and participants to engage in a dialogue in which initial questions are modified in light of the participants' responses and the investigator is able to probe interesting and important areas that arise (Jonathan, Smith \& Osborne 2007).

\section{Sampling}

A purposive sample of 25 first year pre-service teachers was used in this study. These were students at a particular university of technology in the Western Cape studying Bachelor of Education in FP. They are isiXhosa-speaking students and were placed in isiXhosa-medium schools. There were 10 pre-service teachers in Grade R, five in Grade 1, seven in Grade 2 and three in Grade 3. IPA studies are conducted on small sample sizes. Detailed case-by-case analysis of individual transcripts takes a long time, and the 
aim of the case study is to say something in detail about the perceptions and understandings of this particular group rather than prematurely make more general claims (Jonathan et al. 2007).

\section{Data analysis}

The researchers of the study adopted the IPA method of data analysis. IPA concedes that research is a dynamic process and acknowledges that personal worlds of both the researcher and the participants influence the generation of data (Smith, Flowers \& Larkin 2009). The participants are trying to make sense of their world and the researchers are trying to make sense of the participants who are trying to make sense of their world (Jonathan et al. 2007).

They further stated that IPA has a theoretical commitment to the person as a cognitive, linguistic, affective and physical being and assumes a chain of connection between people's talk and their thinking and emotional state.

It also recognises that the quality of data depends on participants' ability to describe and communicate their thoughts, feelings and experiences clearly to the researcher. Larkin et al. (2006) highlight that the outcome of a successful analysis is likely to include an element of giving voice (capturing and reflecting upon the principal claims and concerns of the research participants) and making sense (offering an interpretation of this material.

Data generated were analysed and compared and categorised into themes. IPA participants and the researcher were isiXhosa-speaking people and communicated very clearly about the data generated.

\section{Research findings and discussion}

The participants of the study highlighted two themes:

1. poor understanding of what integrative teaching and learning is

2. lack of resources in isiXhosa to integrate language, life skills and mathematics.

\section{Poor understanding of integrative teaching and learning}

From the non-participant observations of all the lessons and one-on-one interviews, it was evident that all the participants had a poor understanding of what integrative teaching and learning is. There was little or no integration in their lessons. Schafer and Wilmot (2015) relate to this, saying

Teachers narrowly adhere to the national curriculum requirements. We have observed how children in Grade $\mathrm{R}$ spent more time completing worksheets than expressing their understanding through drawing and painting, which we argue, can be an avenue of mathematical learning.

Harlen et al. (2015:47) state that primary school teachers face certain challenges in relation to big ideas in science. Firstly, the activities of young children are generally focused on exploring their local environment and the living and nonliving in it. These investigations and observations lead to 'small' ideas whose connection to big ideas of science may seem tenuous. They are, therefore, likely to be poorly prepared to see the links between the ideas developed in classroom activities. A further difficulty is the lack of confidence in teaching science as a result of little personal exposure to scientific activity and the understanding arising from that experience.

The participants of the study were introduced in assignments to foster such connections and understanding; for example, they were given composition papers in a language lesson that focuses on topics from biology, economics or history; mathematics assignments that apply mathematical tools to important issues and require written analysis to explain the implications and limitations of the mathematical treatment; or art history presentations that demonstrate connections between selected paintings and novels. Students examined a scientific, historical, social problem in depth and distilled its meaning or significance in a metaphor or work of art (e.g. historical monument). All these activities or examples were taught to the participants and it was expected of them to do the same in their FP classroom; however, most of the time the implementation of the integrative learning was not effective.

For example, Student A was teaching a literacy lesson (a poem) to a Grade 2 class; she used a poem about different types of pets which is a life skills theme. She ended up teaching about different types of pets and there was no evidence of a language lesson, for example explaining metaphors, idioms or vocabulary. When she was interviewed for a reflection of her lesson, she could not understand that she taught a life skills lesson instead of a language lesson. In the lesson (language lesson), the student read and recited the poem with the learners. She further discussed about different pets, for example where they live, what they eat and what sounds they make. She did not cover any aspect of language. She further explained that the use of isiXhosa as a language of teaching and learning made her confident that she was teaching a language lesson.

Student B had a lesson where she read a story that had a theme of teaching learners about safety on the road. She went on to teach about how to cross the road and what one must not do when crossing the road, instead of teaching language skills, for example asking questions about what occurred to test listening skills, looking for new vocabulary or awareness of phonics. The student thought because she was using isiXhosa as a medium of instruction, while teaching about pets she had given a language lesson, but in actual fact she gave a life skills lesson in isiXhosa during a language lesson.

\section{Lack of resources used for integration}

One of the challenges identified was a lack of resources in isiXhosa to implement integrative teaching and learning. The researcher observed that participants were using irrelevant 
teaching resources to enhance the integrative teaching and learning. Firstly, they were irrelevant because they were in English; thus, they were asked to create isiXhosa resources. In FP, all the subjects are taught in the mother tongue except English in Grades 1-3. Secondly, the themes of the songs, poems or stories were not relevant to what they were teaching, for example they would sing 'twinkle little star' for a lesson on different modes of transport.

After practice teaching the researchers came up with an intervention to assist participants in creating their own teaching resources. Their own teaching resources were to be written in isiXhosa. They could create flash cards and posters but for this article the focus was isiXhosa children's poems that have themes that integrate with other learning areas.

Participants as part of their course work were asked to create children's poems that show evidence of integrated content with specific themes in mathematics for Grade R-3.

In this project, the researchers not only worked with a variety of literacy skills, such as reading, analysing a poem focusing on repetition, illustration, similes, personification and the theme, but also wanted the participants to successfully navigate the demand of other learning areas such as mathematics and life skills.

Characteristics of children's poetry were explained: that they are short, simple, with pictures, personification, repetition and similes, not forgetting the theme which is the important feature that shows the integration. The pre-service teachers were told that these children's poems will be used as tools to integrate life skills and mathematics. 'Children's literature can provide a starting point for integrating social issues within science, technology and an opportunity to turn everyday events found in the storybooks into meaningful curricular activities for young learners' (Freeman, Feeney \& Moravcik 2011). Langhorst et al. (2013:75) state that a mathematics programme can be embedded in a cycle of stories. The teacher introduces each new module of content by telling a story.

Participants in this study struggled and the researchers intervened and went through creative writing with them, where they created children's poems with participants and analysed them to highlight and demonstrate the integrative teaching and learning.

The following poems (see Figure 1-5) were created by the researchers to demonstrate integrative teaching and learning.

\section{Summary of Poem 1}

The poem is about five shapes, namely square, circle, triangle, rectangle and oval. It tells a story about the shapes being friends and loving each other in spite of their differences. The title Singabahlobo benene means 'we are real friends'. The illustration for this poem shows the shapes smiling with

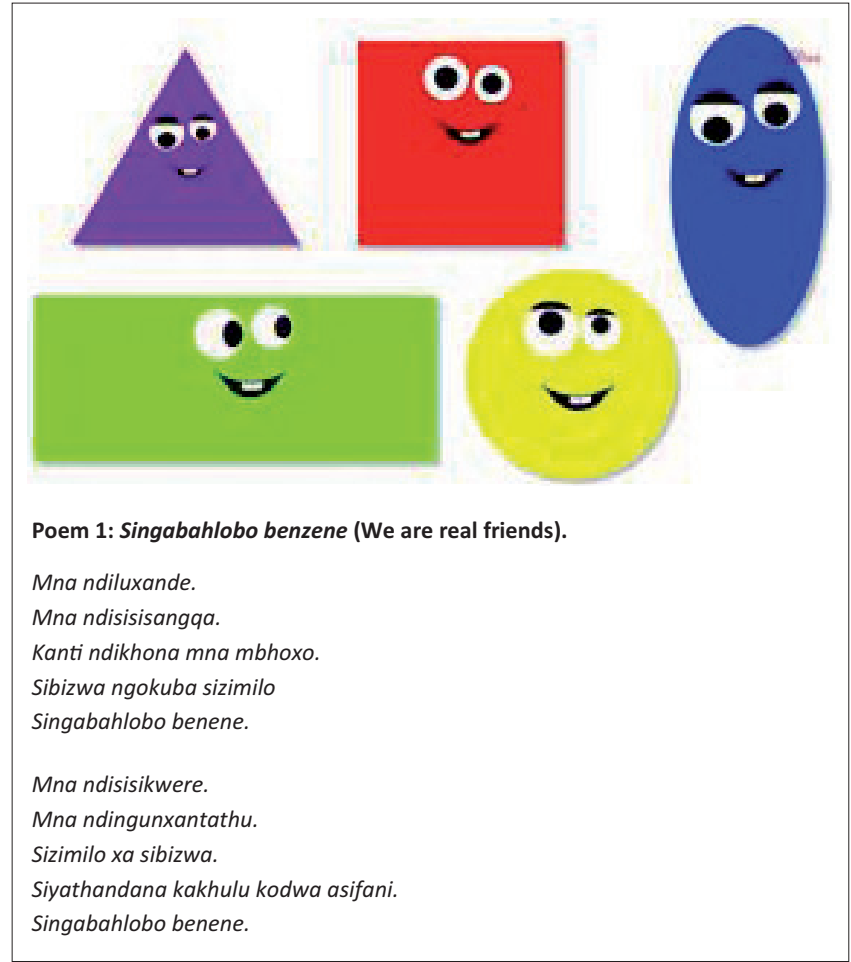

Source: Google Scholar images about shapes.

FIGURE 1: A Life Skills lesson shows shapes as true friends. As much as they are different from one another. The smiles indicates happiness and tolerance. Lastly, in a Mathematic lessons it is about shape awareness.

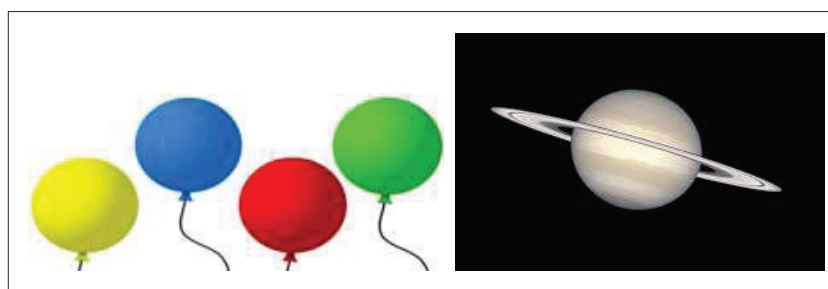

Poem 2: Siyaqaqambisa (We brighten up things).

Ndimhlophe okwekhephu.

Ndibomvu okwegazi.

Ndityheli okwelanga.

Siyaziqaqambisa izinto.

Ndimnyama okwelothe.

Ndiluhlaza okwengca.

Ndiluhlaza okwesibhakabhaka.

Siyazihombisa izinto

Source: Google Scholar images about and colours planets.

FIGURE 2: Different coloursed balloons are used to make the illustration fun because young children learn through play. The insertion of the planet also adds fun for young children.

friendship and happiness and the colours add another aspect of mathematics. The picture can also play an important role in explaining the subject content and enhancing the integrative learning.

\section{Integration of learning areas for Poem 1}

\section{Language lesson}

Mna and Ndi are pronouns for first person and are used as personification of shapes. Repetition of $\mathrm{Mna}$, Ndi, Singabahlobo 


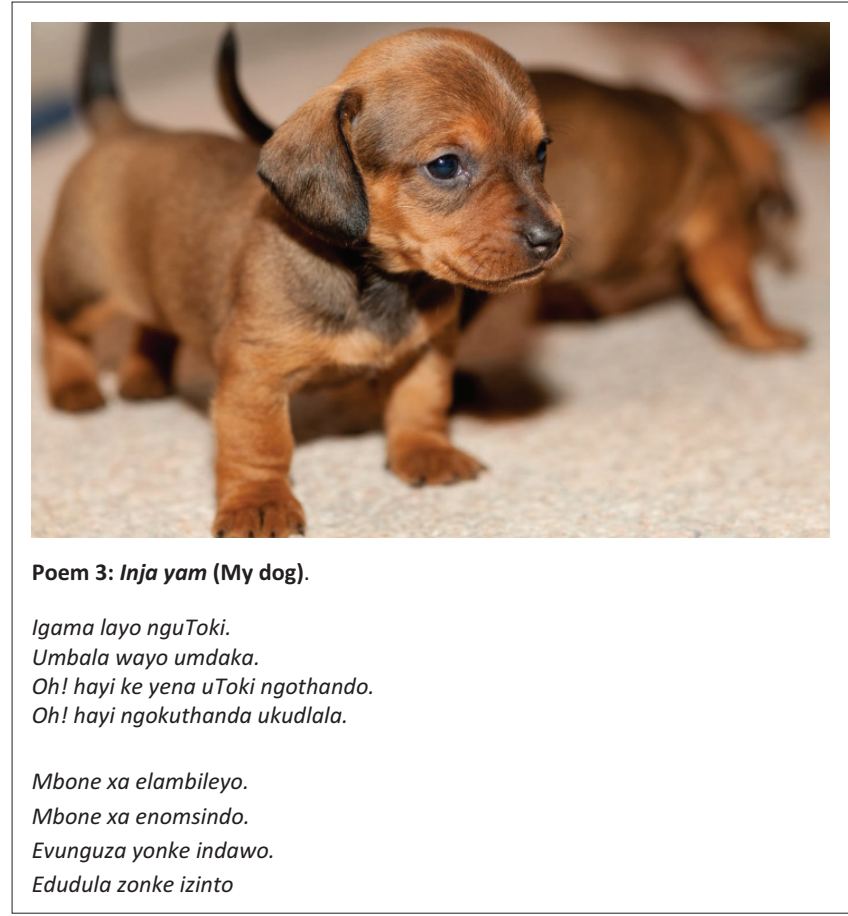

Source: Google Scholar images about types of dogs.

FIGURE 3: Shows us a little puppy that is playing as mentioned in the poem. Also showing the puppy looking a bit angry as it is hungry.

benene in the last lines of the two stanzas creates a rhyme structure to the poem. The theme of the poem is that we can be friends even if we are different. Personification, theme and repetition are aspects of language in this poem.

\section{Integration with other learning areas}

1. Life skills - These shapes pass on the message that they are real friends even though they do not look the same. In life skills, there is a theme 'friendship'. Young children can learn that we need to tolerate each other in spite of our differences.

2. Mathematics - Learning about shapes is part of mathematics and the children will see the pictures and shape awareness occurs.

The teacher can use this poem in teaching these learning areas at any stage of the lesson, for example, to introduce or conclude the lesson.

\section{Summary of Poem 2}

The poem is about colours. They tell a story about themselves and what things are similar to them. The title Siyaqaqambisa means 'we brighten up things'. The colours also compare themselves with nature, that is, white as snow, red as blood and yellow as the sun in the first stanza and black as coal, green as grass and blue as the sky in the second stanza. The illustration for this poem shows objects with the colours mentioned in the poem and these are white, red, yellow, blue, green and black. The awareness of colours is a mathematics aspect and the things that are similar to the colours are aspects of natural science in life skills.

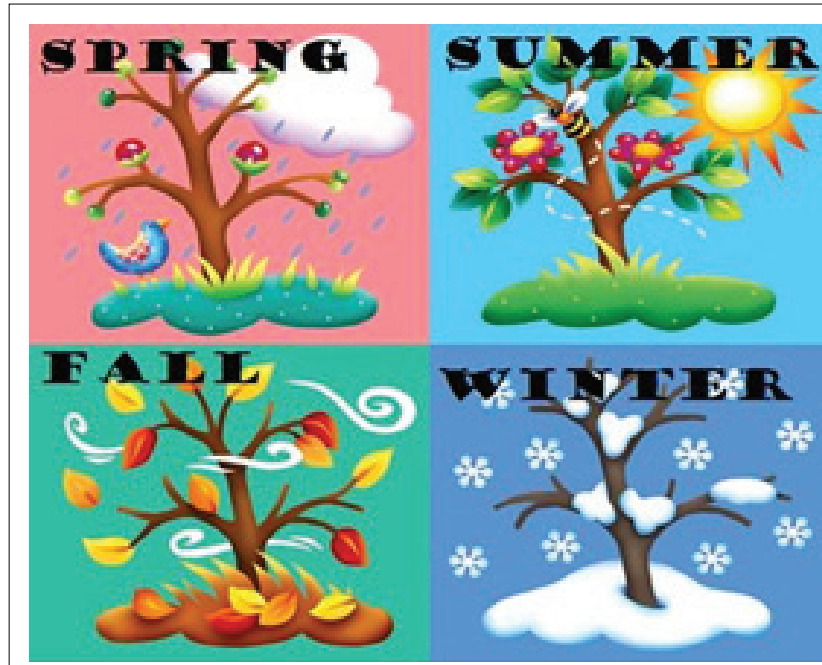

Poem 4: Amaxesha onyaka (Seasons of the year).

Amaxesha onyaka mane kuphela.

Lihlobo nentwasahlobo.

Ukwindla nobusika.

Amaxesha onyaka mane kuphela.

Kushushu ehlotyeni.

lintyatyambo zintle entwasahlobo.

Umoya uyavuthuza ekwindla.

Kuyanda ebusika.

Source: Bing images of seasons.

FIGURE 4: Different seasons of the year.

\section{Integration of learning areas for Poem 2 Language lesson}

$\mathrm{Ndi}$ is a pronoun for first person and it is a personification of colours. Repetition of okwe and Ndi in the two stanzas creates the rhyme in the poem.

One more aspect of language found in this poem is simile that is indicated by okwe, meaning 'it is like' and it is used to indicate what the colours look like in everyday life. The theme of the poem is 'we brighten up things'. Personification, theme, simile and repetition are aspects of language in this poem.

\section{Integration with other learning areas}

1. Life Skills - Aspects of nature like coal, sun, blood, glass, sky and snow are aspects of natural science in life skills.

2. Mathematics - Learning about colours is a part of mathematics and the children will see the colours in the illustration in the poem.

\section{Summary of Poem 3}

The poem is about my pet. It is about my dog. It talks about what a dog looks like. It explains how it behaves. The illustration for this poem shows a dog with the same colour explained in the poem and the way it behaves. 


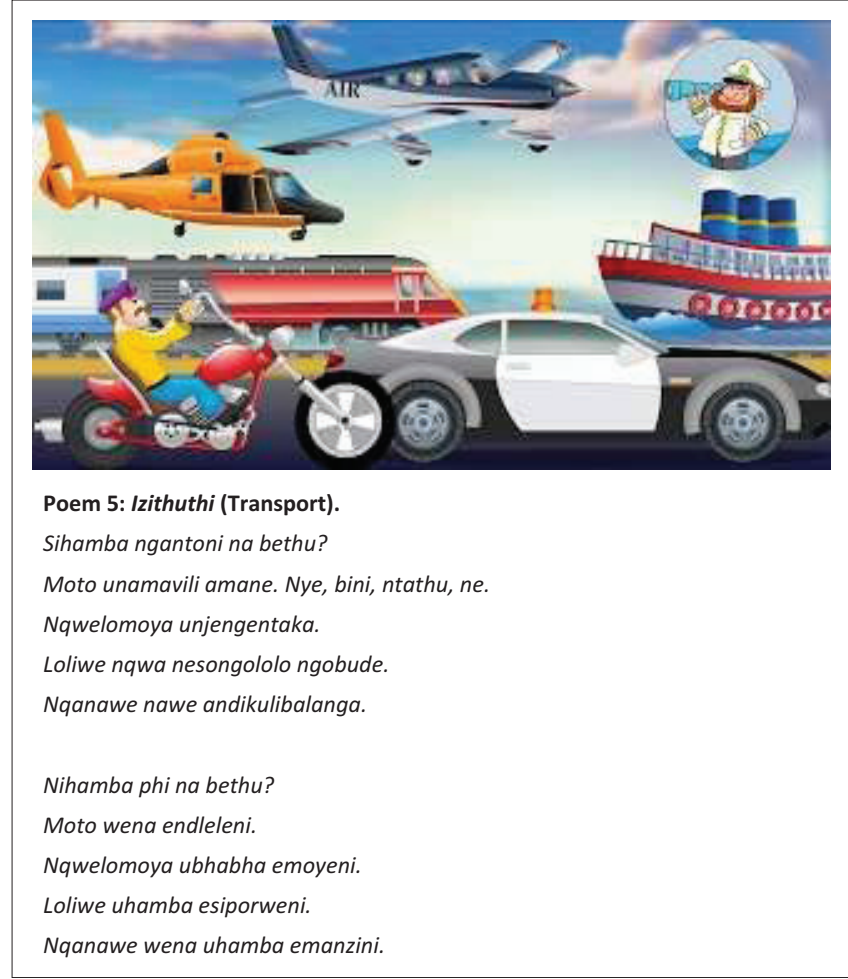

Source: Bing images of different modes of transport.

FIGURE 5: Different modes of transport.

\section{Integration of learning areas for Poem 3}

\section{Language lesson}

Theme and repetition are language aspects that are reflected in this poem. In the first stanza Oh hayi and in the second stanza mbone are repeated to create rhyme in the poem.

\section{Summary of Poem 4}

The poem is about four seasons of the year: summer, winter, spring and autumn. The poem briefly explains what occurs during these seasons. The illustration for this poem shows different events and activities that occur during various seasons.

\section{Integration of learning areas for Poem 4 Language lesson}

The theme of the poem is about different seasons and what occurs during these seasons. In the first stanza, there is repetition of amaxesha onyaka in lines 1and 3 to create a rhyme.

\section{Integration with other learning areas}

1. Life Skills - 'Seasons of the year' is a topic covered in natural science in life skills.

\section{Integration of learning areas for Poem 5 Language lesson}

The theme of the poem is about different types of transport and where they move. In stanzas 1and 2, there is repetition of the verb hamba in the first word sihamba in stanza 1 and nihamba in stanza 2. Na bethu? is repeated in the first line in both stanzas. All the repetition creates rhyming in the poem.

\section{Integration with other learning areas}

1. Life Skills - 'Different modes of transport' is a topic covered in life skills.

\section{Conclusion}

In conclusion, the research showed that children's poetry is good to use to integrate literacy, mathematics and life skills in FP: Grade R-3. Children's poetry enhances the learning experiences and life skills of children in all their classes. It facilitates transitions, allowing the class to move from one activity to the other. The findings of the research conducted revealed that poetry is important in children's lives and education and it integrates language, mathematics and life skills. Through the lens of integrative teaching and learning using children's poetry, the kind of knowledge embedded in isiXhosa poetry is explored. Children's poetry is a very rich perennial reservoir through which FP learners could be taught mathematics and life skills.

\section{Acknowledgements Competing interests}

The authors declare that they have no financial or personal relationships which may have inappropriately influenced them in writing this article.

\section{Authors' contributions}

N.G. was responsible for conceptualisation, methodology, search and compilation of findings as well as write-up of the article. N.S. was responsible for some interpretation of findings as well as write-up of the discussion section of the article.

\section{References}

Choudhury, A., 2016, Participant and non-participant observation, viewed 19 January 2017, from http://www.yourarticlelibrary.com/social-research/data-collection/ participant-observation

Department of Basic Education (DBE), 2011, Curriculum and Assessment Policy Statement (CAPS): Foundation phase mathematics grade $R-3$, Department of Education, Pretoria.

Elliot, P., 2010, Science and literacy in the elementary classroom, Research Monograph 26, The Literacy and Numeracy Secretariat, Ontario.

Freeman, N.K., Feeney, S. \& Moravcik, E., 2011, 'Enjoying a good story: Why we use children's literature when teaching adults', Early Childhood Education Journal 39(1), 1-5. https://doi.org/10.1007/s10643-010-0439-4

Harlen, W. (ed.), 2010, Principles and big ideas of science education, Association for Science Education, Hatfield, UK.

Harlen W., Bell, D., Deves, R., Millar, R., Reiss M., Yu W., et al., 2015, Working with big ideas of science education: IAP the global network of science academies, Science Education Programme of IAP, Italy

Jonathan, S. \& Osborne, J., 2007, Interpretative phenomenological analysis, Sage, London.

Kok, L. \& Van Schoor, R., 2014, 'A science-technology-society approach to teacher education for the foundation phase: Student's empiricist views', South African Journal of Childhood Education 4(1), 95-110. https://doi.org/10.4102/sajce. v4i1.180 
Langhorst, P., Ehlert, A. \& Fritz, A., 2013, 'Realising pre-school mathematical education in a development-oriented math programme with, special consideration of phonological language processing aspects', South African Journal of Childhood
Education 3(1), 39-68. https://doi.org/10.4102/sajce.v3i1.32

Larkin, M., Watts, S. \& Clifton, E. 2006, 'Giving voice and making sense in interpretative phenomenological analysis', Qualitative Research in Psychology 3, 102-120. https://doi.org/10.1191/1478088706qp062oa

Nompula, Y., 2012, 'An investigation of strategies for integrated learning experiences and instruction in the teaching of creative art subjects',
South African Journal of Education 32(3), 293-306. https://doi.org/10.15700/ saje.v32n3a579

Schafer, J. \& Wilmot, D., 2015, 'Visual arts and the teaching of the mathematical concepts of shape and space in Grade R classroom', South African Journal of Childhood Education 5(1), 6284

Smith, J.A., Flowers, P. \& Larkin, M., 2009, Interpretative phenomenological analysis: Theory, research and practice, Sage, London.

Zainal, Z., 2007, 'Case study as a research method', Jurnal Kemanusiaan bil 9, 1-6. 